\title{
Long-Term Outcomes of Pediatric Graves Disease
}

\section{Patients Treated with Anti-Thyroid Drugs: Experience from a Taiwan Medical Center}

\section{Short title}

Long-term outcomes in children and adolescents with Graves disease

Ya-Ting Chiang ${ }^{1,2 \pi}$, Wei-Hsin Ting ${ }^{1,3,4 \pi}$, Chi-Yu Huang ${ }^{1,3}$, Shih-Kang Huang ${ }^{1}$,

Chon-In Chan ${ }^{1}$, Bi-Wen Cheng ${ }^{5}$, Chao-Hsu Lin ${ }^{5}$, Yi-Lei Wu ${ }^{6}$, Chen-Mei Hung7,

Hsin-Jung Li ${ }^{8}$, Chia-Jung Chan ${ }^{9}$, Yann-Jinn Lee ${ }^{1,3,10,11,12^{*}}$

${ }^{1}$ Department of Pediatric Endocrinology, MacKay Children's Hospital, Taipei,

Taiwan

${ }^{2}$ Department of Pediatric Endocrinology, Ditmanson Medical Foundation Chia-Yi

Christian Hospital, Chiayi, Taiwan

${ }^{3}$ Department of Medicine, MacKay Medical College, New Taipei City, Taiwan

${ }^{4}$ MacKay Junior college of Medicine, Nursing and Management, New Taipei City,

Taiwan

${ }^{5}$ Department of Pediatrics, MacKay Memorial Hospital HsinChu, Hsin-Chu, Taiwan

${ }^{6}$ Department of Pediatrics, Changhua Christian Hospital, Chang-Hua, Taiwan 
${ }^{7}$ Department of Pediatrics, Hsinchu Cathay General Hospital, Hsin-Chu, Taiwan

${ }^{8}$ Department of Pediatrics, St. Martin De Porres Hospital, Chiayi, Taiwan

${ }^{9}$ Chiahung Clinic, Taichung, Taiwan

${ }^{10}$ Department of Medical Research, MacKay Memorial Hospital Tamsui, New Taipei

City, Taiwan

${ }^{11}$ Department of Pediatrics, School of Medicine, College of Medicine, Taipei

Medical University, Taipei, Taiwan

${ }^{12}$ Institute of Biomedical Sciences, MacKay Medical College, New Taipei City,

Taiwan

${ }^{*}$ Corresponding author

E-mail: yannlee@mmh.org.tw (Lee YJ)

I These authors contributed equally to this work 


\section{Abstract}

2 Graves disease (GD) is the most common cause of thyrotoxicosis in children and

3 adolescents, accounting for $15 \%$ of all thyroid diseases during childhood.

4 Anti-thyroid drugs (ATD) are recommended as the first-line treatment in children and

5 adolescents. However, the remission rate is lower in children than in adults, and the

6 optimal treatment duration and favorite factors associated with remission remain

7 unknown. We aimed to investigate long-term outcomes of pediatric GD patients

8 receiving ATD. We retrospectively reviewed medical charts of 300 pediatric GD

9 subjects, who were initially treated with ATD and followed up for more than one year,

10 from 1985 to 2017 at MacKay Children's Hospital. The 300 patients comprised 257

11 (85.7\%) females and $43(14.3 \%)$ males, median age at diagnosis was 11.6 (range

12 2.7-17.8) years, and median follow-up period was 4.7 (range 1.1-23.9) years. Overall,

13122 patients achieved the criteria for discontinuing ATD treatment, seventy-nine

14 (39.9\%) patients achieved remission, with a median follow-up period of 5.3 (range

15 1.5-20.1) years. Patients in the remission group were more likely to be aged $<5$ years

16 (remission vs. relapse vs. ongoing ATD; 11.4 vs. 0 vs. $2.6 \%, P=0.02$ ), less likely to

17 have a family history of thyroid disease ( 24.1 vs. 42.1 vs. $52.6 \%, P=0.001)$, and had 
bioRxiv preprint doi: https://doi.org/10.1101/618942; this version posted April 25, 2019. The copyright holder for this preprint (which was

not certified by peer review) is the author/funder, who has granted bioRxiv a license to display the preprint in perpetuity. It is made available under aCC-BY 4.0 International license.

18

lower TRAb levels (42.8 vs. 53.6 vs. $65.1 \%, P=0.02)$. Conclusion: Long-term ATD

19 remains an effective treatment option for GD in children and adolescents. Pediatric

20 GD patients aged $<5$ years, having no family history of thyroid disease and having

21 lower TRAb levels were more likely to achieve remission. 


\section{Introduction}

23 Graves disease (GD) is a common disorder in adults, with a prevalence of

24 approximately $0.5-1 \%$. Pediatric patients account for $<5 \%$ of the total number of GD

25 patients [1]. However, GD remains the most frequent cause of thyrotoxicosis in

26 children and adolescents, accounting for $15 \%$ of thyroid disease during childhood [2].

27 The incidence increases gradually from young children and peaks in adolescents [3].

28 The optimal treatment option for GD in children and adolescents remains

29 controversial. Current treatment approaches for GD include anti-thyroid drugs (ATD),

30 radioactive iodine and surgery. ATD is usually recommended as the first-line

31 treatment for GD in children and adolescents. However, the remission rate is lower in

32 children than in adults $[2,4,5]$; the optimal treatment duration and the favorite factors

33 associated with remission have not yet been established in children and adolescents

$34 \quad[6-8]$.

35 The issue of how long ATD should be used in pediatric GD is important and

36 warrants further study $[5,9]$. In adult GD patients, if remission does not occur after

$37 \quad 12-18$ months of ATD therapy, the chance of remission with prolonged therapy is

38 very low $[4,10]$. In the pediatric population, longer treatment duration is associated 
bioRxiv preprint doi: https://doi.org/10.1101/618942; this version posted April 25, 2019. The copyright holder for this preprint (which was

not certified by peer review) is the author/funder, who has granted bioRxiv a license to display the preprint in perpetuity. It is made available under aCC-BY 4.0 International license.

39 with a higher remission rate. Lipple reported that the median time to remission with

40 ATD was 4.3 years, and the expected remission rate was $25 \%$ every 2 years [11].

41 Leger reported that overall estimated remission rates after withdrawing ATD

42 increased with time and were $20,37,45$, and $49 \%$ after $4,6,8$, and 10 years follow-up,

43 respectively [6]. A retrospective study in Japan revealed that the remission rate was

$4446.2 \%$ after a median duration of 3.8 years [12]. However, long-term remission rate of

45 pediatric GD cases treated with ATD was very low $(<20 \%)$, in cohorts from Australia

46 [13] and Denmark [14].

Pediatric GD patients with some clinical or laboratory characteristics may have a

48 higher chance of remission. A prospective study in France revealed that younger (age

$49<5$ years), non-Caucasian children with severe initial presentation had a higher

50 chance of relapse and required longer ATD treatment [7]. Another prospective study

51 reported that initial less severe hyperthyroidism and the presence of other

52 autoimmune conditions were remission predictors [6]. A similar study in the USA

53 demonstrated that lower total T3, euthyroidism within 3 months of PTU and older age

54 (age $>14.6$ years) were significant remission predictors [8]; however, the largest

55 retrospective study to date did not identify any significant factors to predict remission 
56 [12]. These above studies showed no consistent findings and few studies were

57 conducted in the Asian population.

58 We aimed to investigate the long-term outcomes of pediatric GD patients who

59 received ATD and identify probable clinical or laboratory factors associated with

60 remission. We documented our 32-year experience in 300 children and adolescents

61 with GD. Patients were classified as remission, relapse, and ongoing ATD groups;

62 clinical and laboratory characteristics were presented and analyzed. 


\section{Material and methods}

64 We retrospectively reviewed medical charts of 396 GD subjects from 1985 to 2017 at

65 MacKay Children's Hospital. All the patients were diagnosed before 18 years of age.

66 GD was diagnosed based on clinical and laboratory evidence, including thyrotoxicosis,

67 diffuse goiter, with or without ophthalmopathy, elevated free T4/total T4 and

68 suppressed TSH levels, and presence of autoantibodies against TSH receptor [4, 15].

69 Seventy-one patients were followed for less than one year, 6 patients received

70 radioactive therapy and 19 patients received surgery as definite therapy and thus were

71 excluded from our analyses. The remaining 300 patients initially treated with ATD

72 and followed up for $>1$ year constituted our study population.

We collected the following information from patients' medical charts: age at

(type 1 diabetes, myasthenia gravis) or other syndrome (Down syndrome), initial free 
bioRxiv preprint doi: https://doi.org/10.1101/618942; this version posted April 25, 2019. The copyright holder for this preprint (which was

not certified by peer review) is the author/funder, who has granted bioRxiv a license to display the preprint in perpetuity. It is made available under aCC-BY 4.0 International license.

80 a starting dose between 2.5 and $30 \mathrm{mg} / \mathrm{day},(0.05-0.80 \mathrm{mg} / \mathrm{kg} / \mathrm{day})$ depending on the

81 patients' age, body weight, clinical severity, and initial fT4 levels. PTU was only used

82 when the patients could not tolerate the side effect of carbimazole or methimazole.

83 The dose was subsequently titrated and adjusted to maintain euthyroidism. Patients

84 were initially followed at 2-4 weeks interval and then every 3 months after thyroid

85 function test results normalized. ATD was discontinued if euthyroidism was

86 maintained at a low dose (methimazole $\leq 2.5 \mathrm{mg}$ /day) for more than $6-12$ months, and

87 the TRAb was near or within the normal range. Remission was defined as the

88 maintenance of euthyroidism $\geq 12$ months after ATD was discontinued and no

89 recurrence of thyrotoxicosis was recorded during the follow-up period. Relapse was

90 defined as an elevated fT4, suppressed TSH levels together with restarting ATD use.

91 We obtained informed written consent from the parents or guardians of the

92 children, and the study was approved by Mackay Memorial Hospital institutional

93 review board (18MMHIS156e).

\section{$94 \quad$ Statistical analysis}

95 We preformed descriptive statistics with categorical variables expressed as

96 percentages and continuous variables as medians (25-75 percentiles) or means \pm SD. 
bioRxiv preprint doi: https://doi.org/10.1101/618942; this version posted April 25, 2019. The copyright holder for this preprint (which was

not certified by peer review) is the author/funder, who has granted bioRxiv a license to display the preprint in perpetuity. It is made available under aCC-BY 4.0 International license.

97 Univariate analysis. A comparison of frequencies was performed employing the

98 chi-square test or Fisher's exact test (in case of expected frequencies $<5$ ). A

99 comparison of continuous variables was carried out using One-way ANNOVA or

100 Kruskal-Wallis test while multiple groups were compared.

101 Multivariate analysis. Multivariate logistic regression model was used to identify the

102 possible remission predictors. Variables that were associated with remission in the

103 univariate analysis and those judged to be potentially clinically relevant were entered

104 the model. The variables used in the analysis were the proportion of young patients

105 (age $<5$ years), the proportion of patients with negative family history, initial fT4

106 levels, and TRAb levels at diagnosis. All the statistical analyses were performed using

107 SAS software (version 9.4). 


\section{Results}

109 The 300 patients comprised 257 (85.7\%) females and $43(14.3 \%)$ males. Their median

110 age at diagnosis was 11.6 (range $2.7-17.8$ ), and 11 patients (3.7\%) were diagnosed

111 before the 5 years of age. The age and sex distributions were shown in Fig 1. One

112 hundred and twelve patients (37.3\%) reported a family history of thyroid disease. The

113 median follow-up period of these patients was 4.7 (range 1.1-23.9) years. There were

114102 patients (34\%) who were lost follow-up during the study period. Those who were

115 lost follow-up had no significant differences in the clinical and laboratory

116 characteristics compared with those who remained in the study, except for shorter

117 follow-up period (3.7 vs. 5.3 years, $P=0.004$ ).

Fig 1. Age and sex distribution of children and adolescents with Graves disease

(GD) diagnosis.

121 The 300 patients consisted of 257 females and 43 males. The median age at diagnosis

122 was 11.6 years (range $2.7-17.8$ years). The incidence of GD increased markedly

123 during adolescence. 
bioRxiv preprint doi: https://doi.org/10.1101/618942; this version posted April 25, 2019. The copyright holder for this preprint (which was

not certified by peer review) is the author/funder, who has granted bioRxiv a license to display the preprint in perpetuity. It is made available under aCC-BY 4.0 International license.

127 group. ATD was discontinued in $122(61.6 \%)$ patients who met the criteria for

128 discontinuing ATD treatment. Seventy-nine (39.9\%) patients met the remission

129 criteria, with a median follow-up of 5.3 (range 1.5-20.1) years and were classified as

130 the remission group. Thirty-eight (19.2\%) patients relapsed after ATD was

131 discontinued, with a median of 0.7 (range $0.08-5.2$ ) years and were assigned to the

132 relapse group. The clinical course of the study population was shown in Fig 2.

Fig 2. Clinical course of the study population initially treated with anti-thyroid drug (ATD).

136 Of the 396 GD patients, 71 were followed for $<1$ year, 25 received definite therapy,

137 and were excluded from our analyses. Of the remaining 300 patients, 102 patients

138 were lost to follow-up during the study period. Of the 198 who continued ATD

139 treatment, ATD treatment was subsequently ongoing in $76(38.4 \%)$ and was

140 discontinued in $122(61.6 \%)$ patients who met the criteria of discontinuing ATD. Of

141 the 122 patients who discontinued ATD treatment, 79 (39.9\%) achieved a remission, 
bioRxiv preprint doi: https://doi.org/10.1101/618942; this version posted April 25, 2019. The copyright holder for this preprint (which was

not certified by peer review) is the author/funder, who has granted bioRxiv a license to display the preprint in perpetuity. It is made available under aCC-BY 4.0 International license.

$14238(19.2 \%)$ experienced a relapse, and $5(2.5 \%)$ were lost to follow-up.

144 Patients in the remission group were more likely to be aged $<5$ years (remission

145 vs. relapse vs. ongoing ATD; 11.4 vs. 0 vs. $2.6 \%, P=0.02)$, less likely to have a

146 family history of thyroid disease ( 24.1 vs. 42.1 vs. $52.6 \%, P=0.001)$, and had lower

147 TRAb levels (42.8 vs. 53.6 vs. $65.1 \%, P=0.02)$, (Table 1$)$. In the remission group,

148 patients aged $<5$ years tended to receive ATD for a longer period than those with

149 older age (younger vs. older age group: 7.2 vs. 5.0 years, $P=0.28$ ). The other variables,

150 including male proportion, the proportion of puberty, height, weight and BMI z score,

151 the proportion of patients with other diseases, initial ATD dose, initial serum fT4, and

152 the interval until fT4 and TRAb levels became normal did not show any significant

153 differences across the three groups. 
Table 1. Clinical and Biochemical Characteristics of Four Groups: Remission Group, Relapse Group, and Ongoing Anti-Thyroid Drug

155 Treatment Group

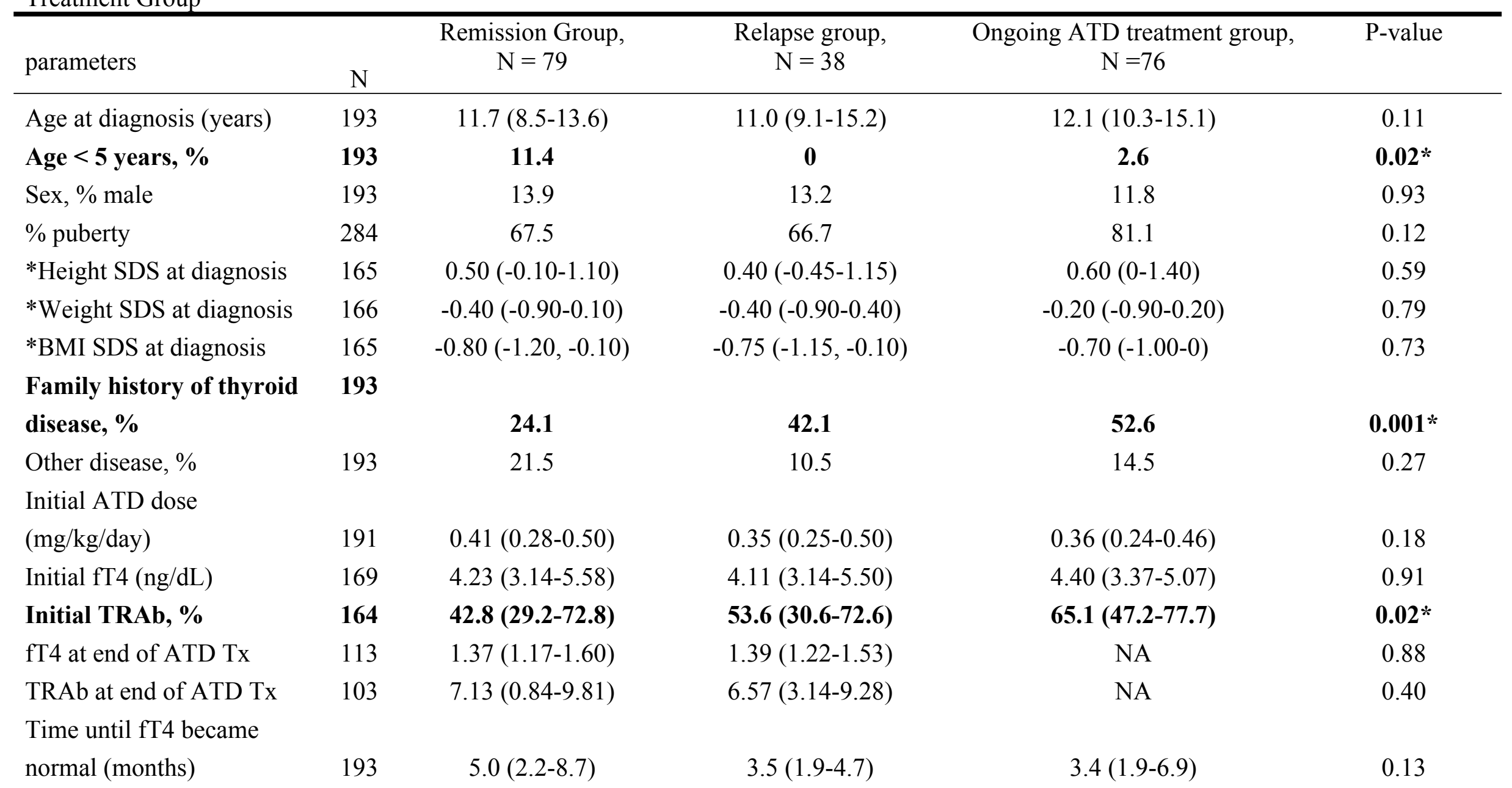


Time until TRAb became

normal (months)

$141 \quad 31.4(17.0-60.5)$

25.8(14.4-34.3)

$24.2(13.3-35.3)$

0.05

Duration of ATD Rx

(years)

183

$5.30(2.90-8.60)$

$7.00(5.60-8.20)$

$4.1(2.40-6.00)$

0.0001

156 Data were Median (25-75 percentile) in continuous variables or percentage in category variables

157 *One-way ANNOVA; Other variables: Kruskal-Wallis Test 
159 were aged $<5$ years (Odds ratio [OR]: 12.6, 95\% confidence interval [CI], 2.19-72.6;

$160 P=0.005)$, had no family history of thyroid disease (OR: $3.75,95 \% \mathrm{CI}, 1.80-7.81 ; P$

$161=0.0004)$, and had a lower initial TRAb levels (OR: 0.98, 95\% CI, 0.97-0.99; $P=$

1620.01 ) as remission predictors in pediatric GD (Table 2). 
Table 2. Factors associated with remission in child and adolescents with Graves disease, multiple logistic regression model

\begin{tabular}{lcccc}
\hline & \multicolumn{2}{c}{ Univariate analysis } & \multicolumn{2}{c}{ Multivariate analysis } \\
\cline { 2 - 5 } Variable & Odds ratio (95\% CI) & P value & Odds ratio (95\% CI) & P value \\
Age $<5$ years & $\mathbf{7 . 2 0}(\mathbf{1 . 5 1 - 3 4 . 3 )}$ & $\mathbf{0 . 0 1}$ & $\mathbf{1 2 . 6 ( 2 . 1 9 - 7 2 . 6 )}$ & $\mathbf{0 . 0 0 5}$ \\
No family history of thyroid disease & $\mathbf{3 . 0 5}(\mathbf{1 . 6 2 - 5 . 7 4 )}$ & $\mathbf{0 . 0 0 1}$ & $\mathbf{3 . 7 5}(\mathbf{1 . 8 0 - 7 . 8 1 )}$ & $\mathbf{0 . 0 0 0 4}$ \\
Initial TRAb, \% & $\mathbf{0 . 9 8 ( 0 . 9 7 - 0 . 9 9 7 )}$ & $\mathbf{0 . 0 1}$ & $\mathbf{0 . 9 8}(\mathbf{0 . 9 7 - 0 . 9 9 )}$ & $\mathbf{0 . 0 1}$ \\
\hline
\end{tabular}




\section{Discussion}

In this study, we demonstrated that patients who aged $<5$ years, who had no

167 family history of thyroid disease and who had lower TRAb levels were more likely to

168 achieve remission. There were 34\% patients who were lost follow-up during the study

169 period. Among patients who continued the ATD treatment, the long-term remission

170 rate in pediatric GD patients was $39.9 \%$ after a median of 5.3 years of ATD treatment.

171 Our results suggested that GD patients who aged $<5$ years had a higher chance

172 to achieve remission and tended to receive ATD for a longer course. These young

173 children were assumed to have better medical adherence under caregivers'

174 surveillance. Previous studies reported that pre-pubertal children needed a longer

175 medical treatment and had a lower remission rate than pubertal children [16]. Lazar et

176 al. reported that the remission rate was not different between pre-pubertal children and

177 adolescents, but the time to remission tended to be longer in pre-pubertal children [17].

178 Two prospective studies showed that younger GD patients were less likely to achieve

179 remission [8] or more likely to relapse after discontinuing ATD [7]. However, other

180 retrospective studies performed in Japan [12] and Taiwan [18] did not determine age

181 as a remission predictor. Because GD is rare in pre-pubertal children, especially in

182 those aged $<5$ years, further studies are needed to clarify the relationship between

183 onset age and remission rate.

184 Our study showed that nearly $40 \%$ of pediatric GD patients had a family history

185 of thyroid disease, consistent with previous studies in the literature $[6,7,12,19]$. Our

186 study also revealed that GD patients with a positive family history of thyroid disease

187 were less likely to achieve remission. A similar study performed in 194 adult GD

188 patients also proved that GD patients with a family history of thyroid disorders were 
2.5 times more likely not to response to ATD treatment [20]. Although not all studies demonstrated a significant association between thyroid disease family history and the

191 chance of remission $[7,8,12,21]$, our study still implied that family history acts as a

192 remission indicator at the time of GD diagnosis.

193 Consistent with previous reports, our study also demonstrated that GD patients

194 with lower titers of TRAb at diagnosis had a higher chance to remission [7, 21, 22].

195 TRAb was reported to be well correlated with GD severity and extra-thyroidal

196 manifestations [23], showing concomitancy with the clinical course and being

197 valuable for the diagnosis and management of children with GD [24]. A retrospective

198 study conducted in 115 children aged $3-15$ years showed that a TRAb level $\leq 2.5$

199 times the upper reference limit, TRAb normalization during ATD and TRAb

200 normalization time may predict further euthyroidism or hypothyroidism after ATD

201 treatment stopped [21]. Pediatric GD patients with non-Caucasian origins, higher

202 TRAb levels, higher free T4 levels, and younger age at diagnosis were reported to

203 have a higher relapse rate [7]. These above studies, combined with our findings,

204 confirmed TRAb as an indicator of GD activity and the predictive role for future

205 remission occurrence after medical therapy.

206 Contradictory to adult GD cases, while a fixed course of ATD (no longer than 18

207 months) was recommended $[25,26]$, most studies showed that a longer ATD

208 treatment duration increased remission rates in pediatric GD [2, 6, 7]. Recent

209 published guidelines therefore suggested a prolonged course of ATD therapy before

210 proceeding to definite therapy [26, 27]. However, the median time to remission

211 reported in the literature was highly variable, and the optimal duration of ATD has not

212 yet been determined. Our treatment protocol resulted in $40 \%$ of remission which is

213 consisted with previous studies $[12,28]$, after a median of 5.3 years of ATD treatment. 
214 As shown in our study, long-term medical therapy resulted in high rates of lost follow

215 up. Some clinicians believe that hypothyroidism is preferable to hyperthyroidism,

216 because it is easier to treat and has a less serious morbidity [29]. However, medical

217 adherence is problematic not only for long-term ATD therapy but also for the

218 thyroxine supplement after hypothyroidism induced by definite therapy [30, 31].

219 Further long-term, prospective studies are required to determine the optimal duration

220 of ATD treatment for pediatric GD.

221 There were several limitations in our study. The first limitation came from its

222 retrospective nature, and high rates of lost follow up, which highlighted the

223 difficulties in the daily practice. Since pediatric GD patients need a protracted ATD

224 course to attain remission, meticulous and realistic counseling of patients and families

225 should be started from the time of diagnosis [31]. Second, we did not analyze the

226 patients' characteristics who receiving radioactive iodine and total thyroidectomy,

227 because few patients chose definite therapy in our institute, even in the relapse group.

228 Third, the documentation of a family history of thyroid disease is not limited to

229 autoimmune thyroid disease, which might introduce some bias to our estimate. Finally,

230 the definition of remission is euthyroidism for only 12 months after ATD is

231 discontinued. It is possible that patients experienced relapse one year after

232 discontinuing medication. However, previous studies indicated that the risk of relapse

233 declines with times [7, 12].

234 In conclusion, we identified pediatric GD patients who aged $<5$ years, had no

235 family history of thyroid disease and had lower TRAb levels were more likely to

236 achieve remission. These remission predictors helped us to discuss with patients and

237 families in the process of shared decision making and treatment plan. Long-term ATD

238 is still a treatment option for pediatric GD, because our study showed that it resulted 
239 in a remission rate of $40 \%$, with a median of 5.3 years ATD course. Such a long-term

240 treatment course was inevitably associated with a poor medical adherence, realistic

241 discussion and consultation should be applied in every newly diagnosed pediatric GD

242 patients.

243

244 Acknowledgments

245 This study was supported by grants RD1050151 from Mackay Medical College; and

246 MMH 108-119 and MMH E-108-7 from MacKay Memorial Hospital, Taipei,

247 Taiwan. 


\section{References}

249 1. Abraham-Nordling M, Bystrom K, Torring O, Lantz M, Berg G, Calissendorff J, 250 et al. Incidence of hyperthyroidism in Sweden. Eur J Endocrinol. 2011;165(6):899-905. doi: 10.1530/EJE-11-0548. PubMed PMID: 21908653.

2. Leger J, Kaguelidou F, Alberti C, Carel JC. Graves' disease in children. Best Pract Res Clin Endocrinol Metab. 2014;28(2):233-43. doi: 10.1016/j.beem.2013.08.008. PubMed PMID: 24629864.

3. Lavard L, Ranlov I, Perrild H, Andersen O, Jacobsen BB. Incidence of juvenile thyrotoxicosis in Denmark, 1982-1988. A nationwide study. Eur J Endocrinol.

4. DAVIES TF, LAURBERG P, BAHN RS. Hyperthyroid disorders. In: Melmed S, MBChB, MACP; , Polonsky KS, MD; , Larsen PR, MD, FRCP; , Kronenberg HM, MD, editors. Williams Textbook of Endocrinology, Thirteenth Edition. Philadelphia, PA 19103-2899: Elsevier; 2016. p. 369-415.

5. Kaguelidou F, Carel JC, Leger J. Graves' disease in childhood: advances in management with antithyroid drug therapy. Horm Res. 2009;71(6):310-7. doi: 10.1159/000223414. PubMed PMID: 19506387.

6. Leger J, Gelwane G, Kaguelidou F, Benmerad M, Alberti C, French Childhood Graves' Disease Study G. Positive impact of long-term antithyroid drug treatment on the outcome of children with Graves' disease: national long-term cohort study. PMID: 22031519.

7. Kaguelidou F, Alberti C, Castanet M, Guitteny MA, Czernichow P, Leger J, et al.

271 Predictors of autoimmune hyperthyroidism relapse in children after 
discontinuation of antithyroid drug treatment. J Clin Endocrinol Metab. 2008;93(10):3817-26. doi: 10.1210/jc.2008-0842. PubMed PMID: 18628515.

8. Glaser NS, Styne DM, Organization of Pediatric Endocrinologists of Northern California Collaborative Graves' Disease Study G. Predicting the likelihood of remission in children with Graves' disease: a prospective, multicenter study. Pediatrics. 2008;121(3):e481-8. doi: 10.1542/peds.2007-1535. PubMed PMID: 18267979.

9. Rivkees SA. Pediatric Graves' disease: controversies in management. Horm Res Paediatr. 2010;74(5):305-11. doi: 10.1159/000320028. PubMed PMID: 20924158.

10. Weetman AP. Graves' hyperthyroidism: how long should antithyroid drug therapy be continued to achieve remission? Nat Clin Pract Endocrinol Metab. 2006;2(1):2-3. doi: 10.1038/ncpendmet0068. PubMed PMID: 16932244. long term medical therapy: twenty-five percent remission every two years. J Clin Endocrinol Metab. 1987;64(6):1241-5. doi: 10.1210/jcem-64-6-1241. PubMed

12. Ohye H, Minagawa A, Noh JY, Mukasa K, Kunii Y, Watanabe N, et al. retrospective study at a single institution. Thyroid. 2014;24(2):200-7. doi:

292 13. Jevalikar G, Solis J, Zacharin M. Long-term outcomes of pediatric Graves' disease. J Pediatr Endocrinol Metab. 2014;27(11-12):1131-6. doi: 10.1515/jpem-2013-0342. PubMed PMID: 24945422. Juvenile Thyrotoxicosis in Denmark: A Nationwide Study, 1998-2012. Horm Res 
Paediatr. 2015;84(2):102-7. doi: 10.1159/000430985. PubMed PMID: 26111962. HLA-DQA1*0501 with Graves' disease in English Caucasian men and women. 8706297.

16. Shulman DI, Muhar I, Jorgensen EV, Diamond FB, Bercu BB, Root AW. Autoimmune hyperthyroidism in prepubertal children and adolescents: comparison of clinical and biochemical features at diagnosis and responses to medical therapy. Thyroid. 1997;7(5):755-60. doi: 10.1089/thy.1997.7.755. PubMed PMID: 9349579.

17. Lazar L, Kalter-Leibovici O, Pertzelan A, Weintrob N, Josefsberg Z, Phillip M. Thyrotoxicosis in prepubertal children compared with pubertal and postpubertal patients. J Clin Endocrinol Metab. 2000;85(10):3678-82. doi:

18. Leu SW, Chi CS, Shu SG. Outcome of antithyroid medication and radioiodine therapy in pediatric Graves' disease. Acta Paediatr Taiwan. 2003;44(4):220-6. PubMed PMID: 14674226.

19. Manji N, Carr-Smith JD, Boelaert K, Allahabadia A, Armitage M, Chatterjee VK,

318 20. Dauksiene D, Dauksa A, Mickuviene N. Independent pretreatment predictors of 319 Graves' disease outcome. Medicina (Kaunas). 2013;49(10):427-34. PubMed PMID: 24709784.

321 21. Gastaldi R, Poggi E, Mussa A, Weber G, Vigone MC, Salerno M, et al. Graves 
disease in children: thyroid-stimulating hormone receptor antibodies as remission markers. J Pediatr. 2014;164(5):1189-94 e1. doi: 10.1016/j.jpeds.2013.12.047. PubMed PMID: 24518168.

22. Vitti P, Rago T, Chiovato L, Pallini S, Santini F, Fiore E, et al. Clinical features of patients with Graves' disease undergoing remission after antithyroid drug treatment. Thyroid. 1997;7(3):369-75. doi: 10.1089/thy.1997.7.369. PubMed PMID: 9226205.

23. Diana T, Brown RS, Bossowski A, Segni M, Niedziela M, Konig J, et al. Clinical relevance of thyroid-stimulating autoantibodies in pediatric graves' disease-a

24. Shibayama K, Ohyama Y, Yokota Y, Ohtsu S, Takubo N, Matsuura N. Assays for multicenter study. J Clin Endocrinol Metab. 2014;99(5):1648-55. doi: 10.1210/jc.2013-4026. PubMed PMID: 24517152.

25. Abraham P, Avenell A, Park CM, Watson WA, Bevan JS. A systematic review of drug therapy for Graves' hyperthyroidism. Eur J Endocrinol. 2005;153(4):489-98. doi: 10.1530/eje.1.01993. PubMed PMID: 16189168.

26. Ross DS, Burch HB, Cooper DS, Greenlee MC, Laurberg P, Maia AL, et al. 2016 American Thyroid Association Guidelines for Diagnosis and Management of Hyperthyroidism and Other Causes of Thyrotoxicosis. Thyroid. 2016;26(10):1343-421. doi: 10.1089/thy.2016.0229. PubMed PMID: 27521067.

27. Committee on Pharmaceutical Affairs JSfPE, the Pediatric Thyroid Disease Committee JTA, Minamitani K, Sato H, Ohye H, Harada S, et al. Guidelines for the treatment of childhood-onset Graves' disease in Japan, 2016. Clin Pediatr 
Endocrinol. 2017;26(2):29-62. doi: 10.1297/cpe.26.29. PubMed PMID: 28458457; PubMed Central PMCID: PMCPMC5402306.

28. Azizi F, Amouzegar A. Management of thyrotoxicosis in children and adolescents: 35 years' experience in 304 patients. J Pediatr Endocrinol Metab. 2018;31(2):159-65. doi: 10.1515/jpem-2017-0394. PubMed PMID: 29306930.

29. Leger J, Carel JC. Hyperthyroidism in childhood: causes, when and how to treat. J Clin Res Pediatr Endocrinol. 2013;5 Suppl 1:50-6. doi: 10.4274/jcrpe.854. PubMed PMID: 23154161; PubMed Central PMCID: PMCPMC3608005.

30. Kourime M, McGowan S, Al Towati M, Ahmed SF, Stewart G, Williamson S, et al. Long-term outcome of thyrotoxicosis in childhood and adolescence in the west of Scotland: the case for long-term antithyroid treatment and the importance of initial counselling. Arch Dis Child. 2018;103(7):637-42. doi: PMCID: PMCPMC6047164.

361 31. Cheetham T, Lane L. Graves' disease. Time to move on. Arch Dis Child. 2018. doi: 10.1136/archdischild-2017-314486. PubMed PMID: 29348117 


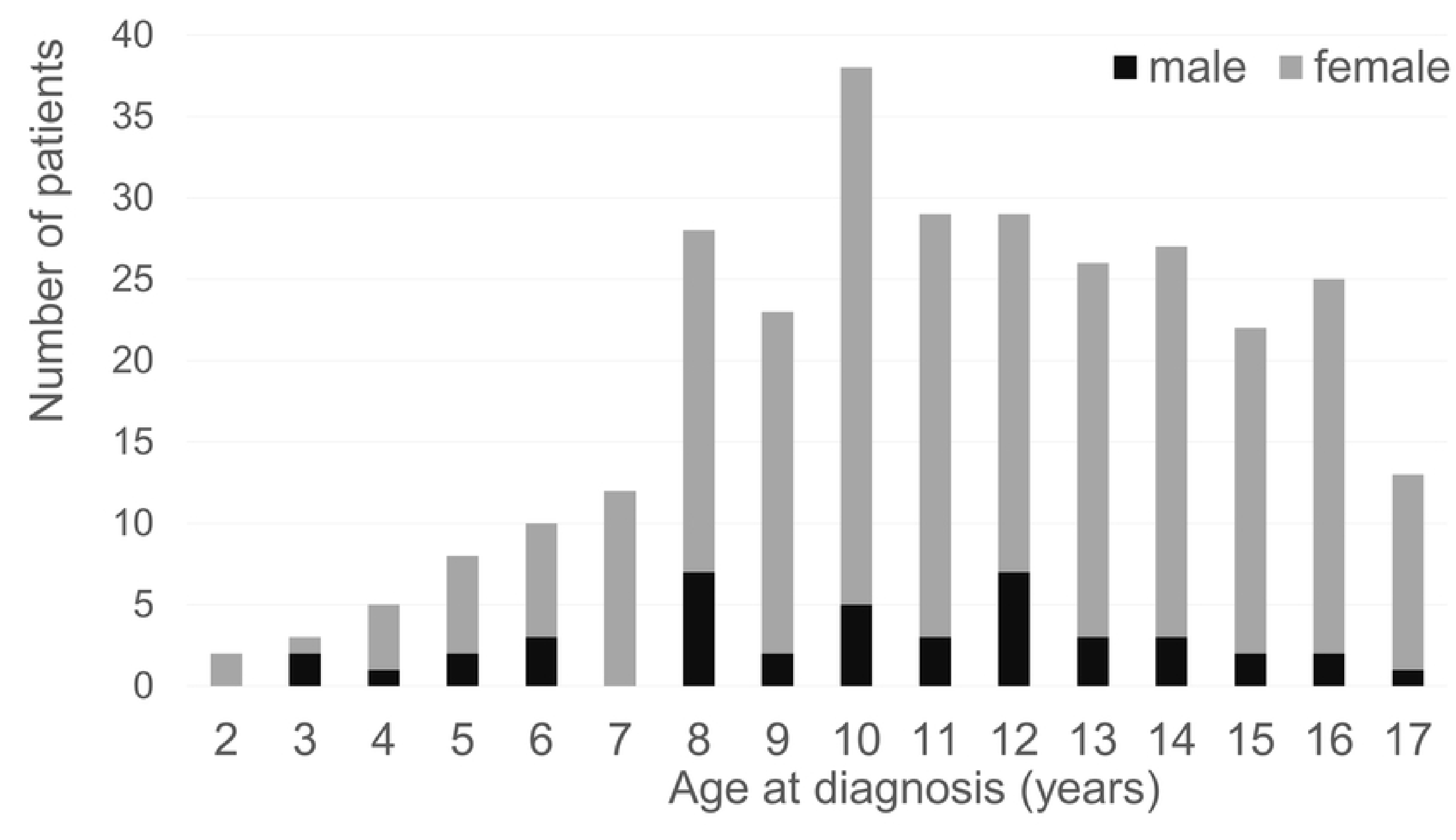

Fig1 


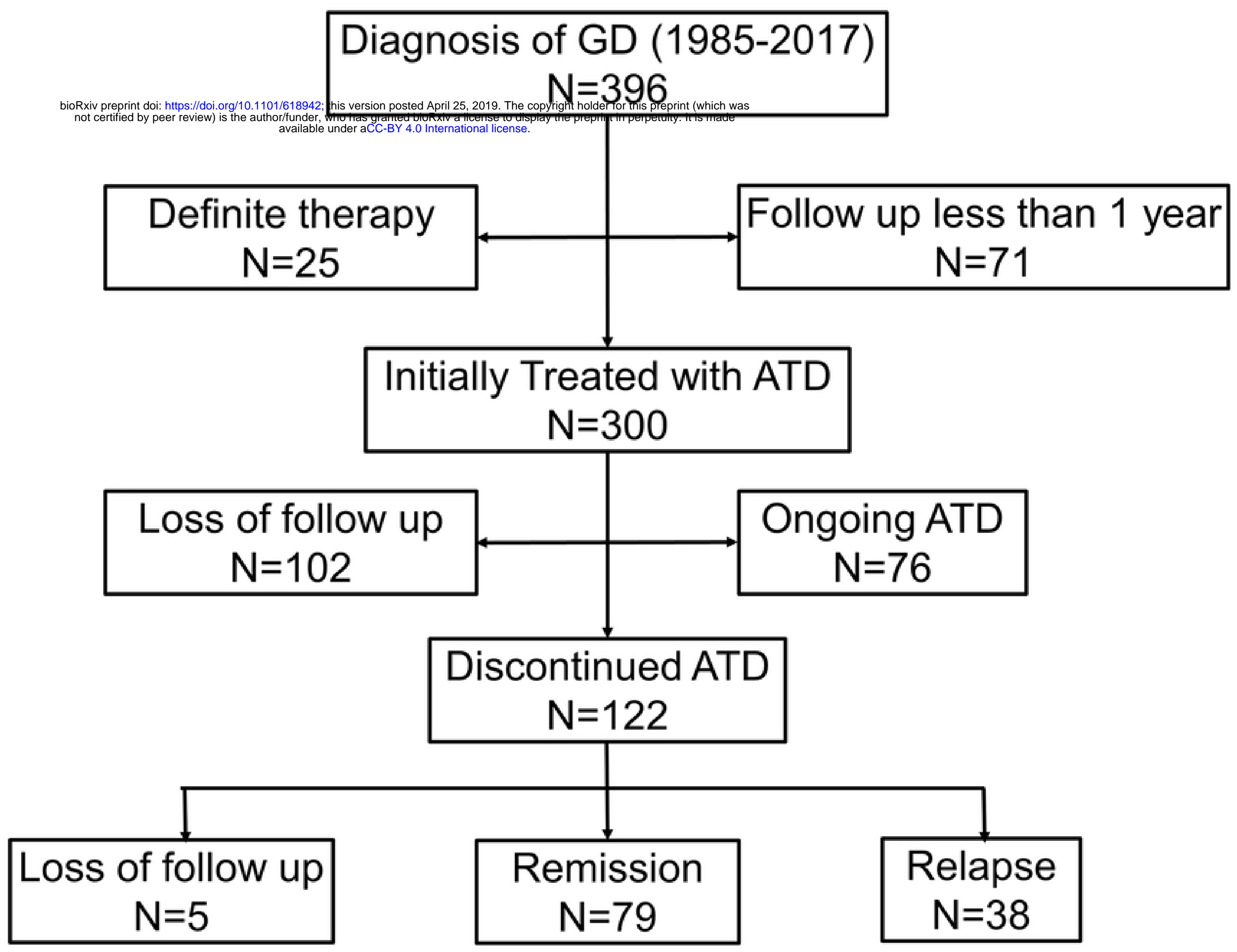

Fig2 